\title{
Behaviour of steel beam subjected to the fire
}

\author{
Lucia Figuli ${ }^{1, *}$ Bohus Leitner ${ }^{1}$ and Paulina Magdolénová ${ }^{1}$ \\ ${ }^{1}$ University of Zilina, Faculty of Security Engineering, Univerzitna 8215/1, 01026 Zilina, Slovakia
}

\begin{abstract}
Fire as one of the extraordinary load is essential to study in all its aspects. It evolve to study the fire development as well as the structural analysis of elements subjected to the fire. The present paper deals with steel beam fire resistance determination by these two approaches (analytical and numerical) and compares the results.
\end{abstract}

\section{Introduction}

The difference in structure loading by fire depends on the different phases of the fire that we recognize. In the first phase of the fire (pre-flashover) the temperature remains relatively low and the structural elements are not more stressed by temperature. The fire produces flue gases that rise up. At the critical temperature, the flue gases are ignited also and the air access is increased via damaged windows. The temperature rises rapidly, the second phase of fire (flesh over) occurs and the temperature load on the structure is extreme. The length of the third phase (post-flashover) depends on the amount of combustible material and the supply of oxygen.

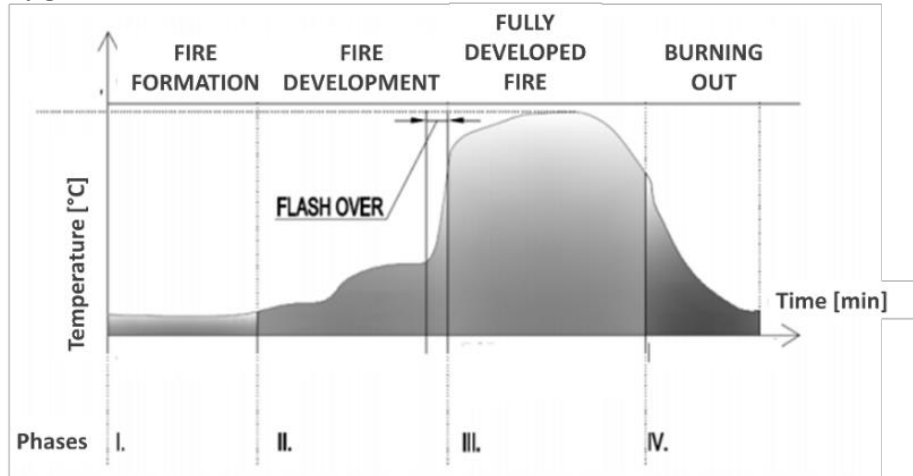

Fig. 1. Temperature development in different phases of the fire [1].

Analysing fire loaded structures 4 main groups of problems have to be solved:

- Selection of the design fire scenario to describe the real expected load

- Determination of the corresponding design fire

- Calculation of temperature development in structural elements

- Calculation of the mechanical behaviour of structure subjected to fire

\footnotetext{
* Corresponding author: lucia.figuli@,fbi.uniza.sk
} 
Various researcher were focused on the structural response under the fire load. Louter et al. [3] conducted research on structural response of fire-exposed laminated glass beams, Vedrtnam et al. in [4] studied the compressive behaviour of sustainable cement-based composites under one-hour of direct flame exposure, Bedon studied fire resistance of in-plane compressed log-house timberwalls with partial thermal insulation in [5]. Behaviour and design of eccentrically loaded hot-rolled steel SHS and RHS stub columns at elevated temperatures was described in [6], Non-linear analysis of composite beam subjected to fire was done in [7].

Fire load modes are described in EN 1991-1-2, which shows simplified and improved models [8]. Simplified fire models are sufficient for general practice but they are limited in size of the fire sections, in size of the fire load and distribution of thermal energy. Improved models consider more exact thermal and temperature distribution in fire section [9]. The most used curves is normal temperature curve, expressing the cellulose burning. The simplest fire models are nominal temperature curves indicating of dependence gas temperature on time in the fire section. Nominal temperature curve (Fig. 2) indicates fire section temperature dependence only on time of fire [8].

$$
\theta_{t}=20+345 \log _{10}(8 t+1)
$$

When $\theta_{t}$ is gas temperature in relevant fire section $\left[{ }^{\circ} \mathrm{C}\right]$ and $t$ is time [min].

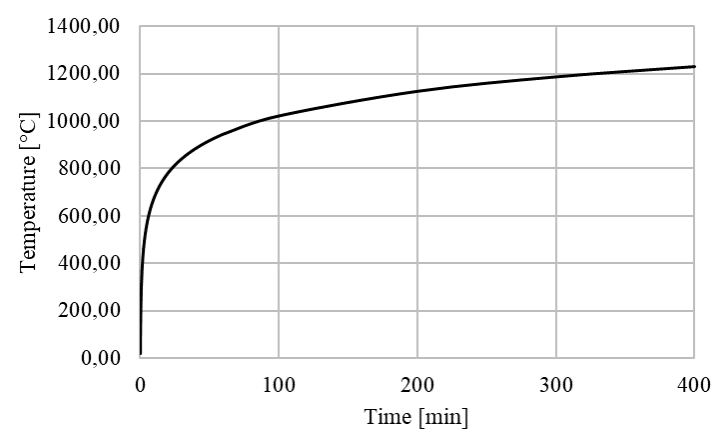

Fig. 2. Nominal temperature curve.

\section{Fire loaded beam analysis}

According to [8], the fire resistance of a steel beam under thermal loading by nominal temperature curve can be determined by a standard calculation or a numerical model. The paper deals with chosen steel beam fire resistance determination by these two approaches and compares the results.

\subsection{Beam description and material properties}

The analysed beam is a part of composite steel-concrete frame construction of a car park. The beam is $12 \mathrm{~m}$ long and acts as a simply supported beam that is characterized by hinged support at each end. The chosen beam is designed for $85 \%$ utilization rate according to applied loading cases determined for car park. The beam cross-section is HEB500 of S355 steel grade. 


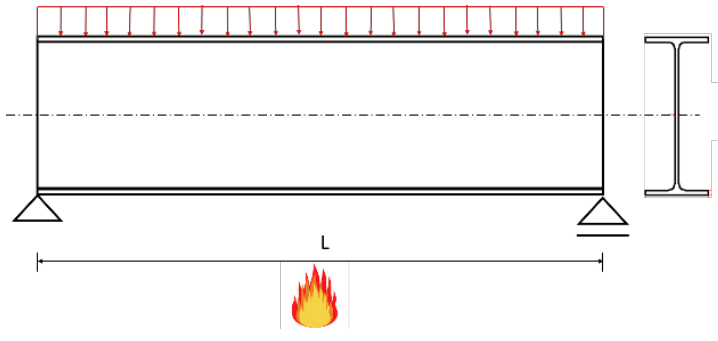

(a)

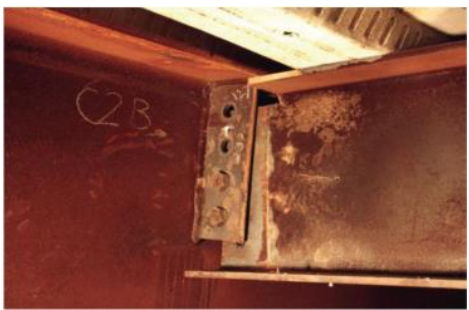

(b)

Fig. 3. Analysed beam (a) disposition (b) connection to the pillar [2].

The change in material properties of steel dependent on risen temperature is considered in both, standard calculation and numerical model. The values of temperature dependent properties are determined by [2] and are presented in Table 1. Bulk density of steel is constant under thermal load with value $7850 \mathrm{~kg} \cdot \mathrm{m}^{-3}$.

Table 1. Mechanical properties during the temperature changing.

\begin{tabular}{|c|c|c|c|c|c|c|c|c|c|}
\hline $\begin{array}{c}\text { Time } \\
{[\text { min : sek] }}\end{array}$ & 0 & $0: 30$ & 1:00 & 5:00 & $10: 00$ & $15: 00$ & 20:00 & $25: 00$ & $30: 00$ \\
\hline $\begin{array}{c}\text { Temperature } \\
{\left[{ }^{\circ} \mathrm{C}\right]}\end{array}$ & 20 & 261 & 349 & 576 & 678 & 739 & 781 & 815 & 842 \\
\hline Specific Heat $\left[{\left.\mathrm{J} . \mathrm{kg}^{-1} . \mathrm{K}^{-1}\right]}^{-}\right.$ & 439.8 & 443.5 & 450.8 & 531.3 & 622.7 & 761.7 & 1003.7 & 3169.9 & 852.4 \\
\hline $\begin{array}{c}\text { Thermal conductivity } \\
{\left[\mathrm{W} \cdot \mathbf{m}^{-1} \cdot \mathbf{K}^{-1}\right]}\end{array}$ & 53.5 & 46.3 & 43.7 & 33.7 & 32.4 & 29.2 & 28.6 & 27.3 & 27.3 \\
\hline Elastic modulus $\left[10^{10} \mathrm{~Pa}\right]$ & 21.1 & 19.95 & 15.78 & 10.09 & 5.48 & 3.98 & 2.94 & 2.1 & 1.87 \\
\hline
\end{tabular}

According to fire safety standards in Slovakia, the beam must withstand the fire load for 30 minutes. This means that the fire resistance R30 of unprotected steel beam will be analysed. The loading for fire resistance analysis is determined according to [8] for extraordinary loading case combination with bending moment value $M_{f i, d}=880 \mathrm{kNm}$.

\subsection{Fire resistance by standard calculation}

The assessment of fire resistance is based on the resistance of the element and is verified by meeting the condition for bending stress:

$$
M_{f i, d} \leq M_{f i, R d}
$$

where $M_{f i, R d}$ is the element bending resistance reduced by risen temperature according to changes in material properties (Table 1). 
The steel temperature was determined according to [8] and nominal temperature curve (Fig.2) for beam flanges and beam web. The values of steel temperature during the time of fire is shown in Fig. 4.

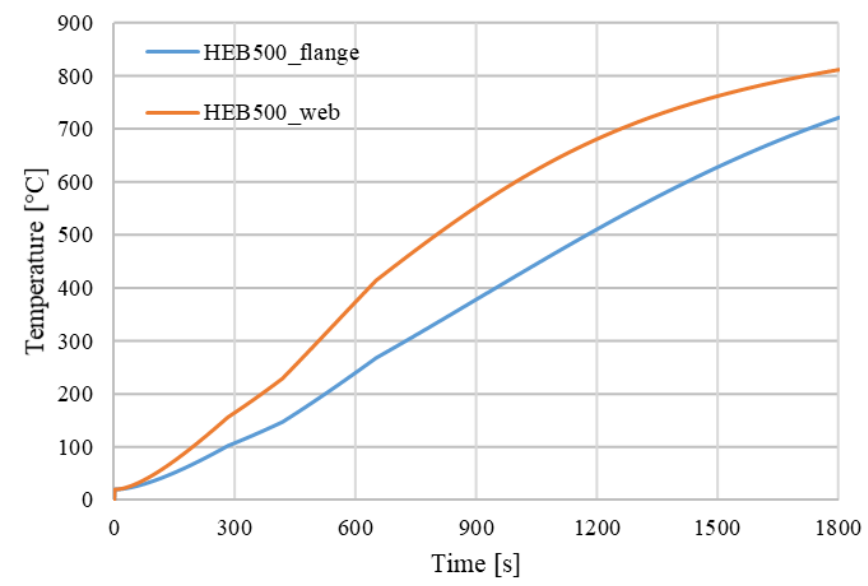

Fig. 4. Steel beam temperature.

\subsection{Fire resistance by numerical model}

By numerical approach of fire resistance analysis, deformation of analysed element is monitored. The time of the element fire resistance is by horizontal beams characterized by exceeding limits of vertical deflection $D[\mathrm{~mm}]$ and the deflection rate $d D / d t[\mathrm{~mm} / \mathrm{min}]$. The limiting values are specified by STN EN 1363-1:

$$
\begin{aligned}
D & =\frac{L^{2}}{400 \cdot d} \\
\frac{d D}{d t} & =\frac{L^{2}}{9000 \cdot d}
\end{aligned}
$$

where $L$ is the beam length and $d$ is the beam height. In this case, the beam height is $630 \mathrm{~mm}$ considering the height of steel beam together with height of concrete slab $130 \mathrm{~mm}$. The beam was modelled in Ansys software which is based on Finite Element Method (FEM) numerical analysis. The model mesh consists of 60699 nodes and 10200 elements and is shown in Fig. 5.

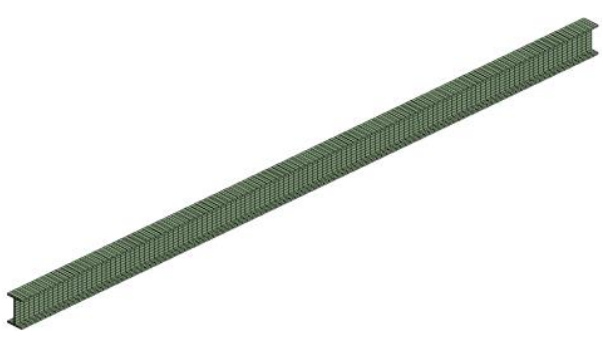

(a)

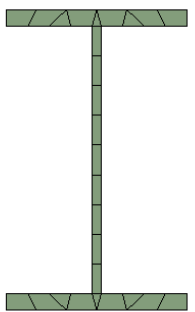

(b) 
Fig. 5. Numerical model mesh: whole beam (a); cross-section (b).

The fire resistance analysis was carried out in two steps: (i) thermal analysis (steel temperature in Fig. 5 applied), (ii) mechanical response analysis.

\section{Results}

The result bending resistance of analysed beam by standard calculation is $M_{f i, R d}=569 \mathrm{kNm}$. According to the result, the condition (2) is exceeded and the beam does not fulfil the R30 fire resistance requirement. The result of numerical model thermal analysis is shown in Fig. 6.
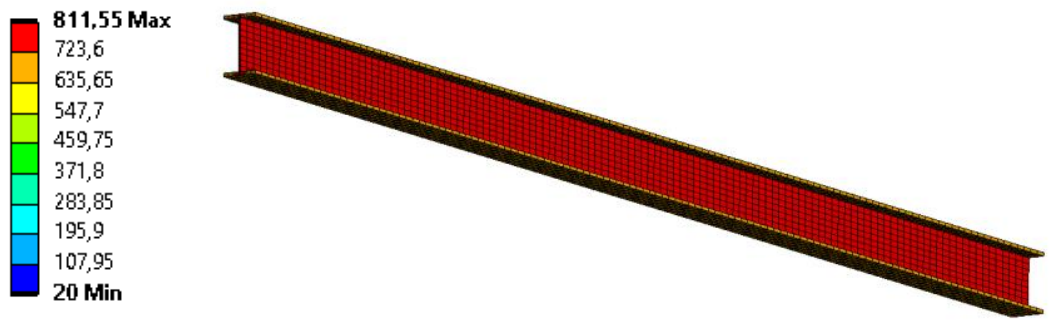

Fig. 6. Steel beam temperature after thermal analysis in time $t=1800 \mathrm{~s}$.

The limiting values of vertical deflection and deflection rate calculated by (3) and (4) are: $D$ $=571.4 \mathrm{~mm}$ and $d D / d t=25.4 \mathrm{~mm} / \mathrm{min}$. As can be seen in Fig. 7, where the deflection development is shown, the limiting value of deformation is not exceeded.

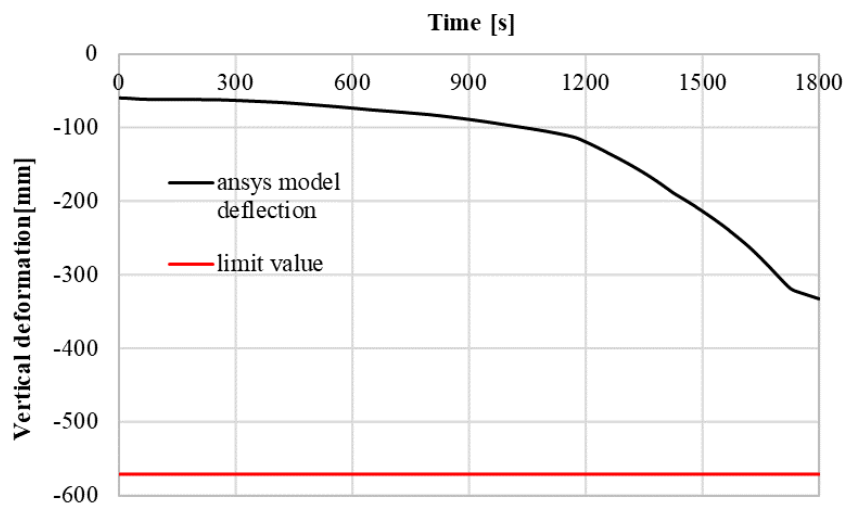

Fig. 7. Numerical model deformation. 

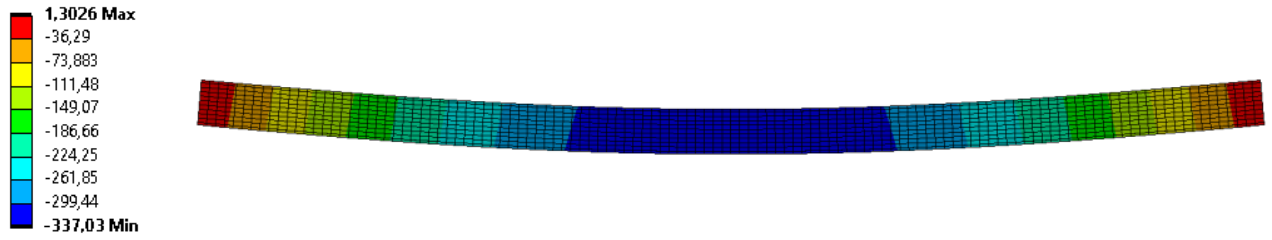

Fig. 8. Beam model deformation after mechanical response analysis in time $t=1800 \mathrm{~s}$.

The maximum value of deflection rate during the analysis is $32.6 \mathrm{~mm} / \mathrm{min}$ which exceeds the limiting value. Since only one limiting condition is exceeded, the beam is considered to withstand the R30 fire resistance requirement.

\section{Conclusions}

Presented research is part of the research developed at Faculty of Security Engineering. The paper is aimed on the analysing of behaviour of the unprotected steel beam loaded by fire. To increase the fire resistance of structure is considered to do various methods of protection of beam section. Fire protection in various types of structures can be found in [5] or using flame retardants described here [6-8].

\section{References}

1. R. Erdelyiova, L. Figuli, M. Ivanco. MATEC Web of Conferences 313, 00033 (2020)

2. R. Erdelyiova, B. Leitner, M. Ivanco, Transportation Research Procedia, 40 pp. 13111318 (2019)

3. C. Louter, Bedon, C., Kozłowski, M., Nussbaumer, A. Fire Safety Journal

4. $123,103353(2021)$

5. A. Vedrtnam, Bedon, C., Barluenga, G. Sustainability (Switzerland) 12(24), 548, pp. 124 (2020)

6. C. Bedon, Fragiacomo, M. Buildings 8(10),131 (2018)

7. X. Yun, Saari, N., Gardner, L. Thin-Walled Structures 149,106646 (2020)

8. M.A. Shallal, Al Musawi, A.M.K. Journal of Engineering and Applied Sciences 13(22), pp. 9643-9650 (2018)

9. EN 1991-1-2 Eurocode 1: Actions on structures. Part 1-2: General actions - Actiones to structures exposed to fire

10. M. Handrik, Vasko, M., Kopas, P. and Mózer, V. MMS Procedia Engineering, pp. 359364 (2016)

11. S. Gasperova, L. Makovicka Osvaldova. Civil and environmental engineering: scientific technical journal, 11 (1), pp.51-57 (2015)

12. L. Makovicka Osvaldova, A. Osvald. Advance Materials Research, 690-693, pp. 13311334. (2013)

13. P. Kadlicova, S. Gasperova, L. Makovicka Osvaldova. Procedia Engineering, 192, pp. 393-398 (2017)

14. M. Gasparik, L. Makovicka Osvaldova, H. Cekovska, D. Potucek. Bioresources, 12, pp. 8451-8467 (2017) 